\title{
Study on Homogenization Annealing of Brass Wire with Electroplated Zinc
}

\author{
P.S. Basak \\ Director, Gradient Wire Products Pvt. Ltd., West Bengal 711 302, India.
}

\begin{abstract}
Extensive experiments of diffusion annealing on zinc plated brass wire have been carried out in the temperature range between $120^{\circ} \mathrm{C}$ and $280^{\circ} \mathrm{C}$. The zinc rich diffused layer at the surface of the wire grows in the initial period of annealing and penetrates into the base of the wire. The diffusion process becomes sluggish and thickness of diffused layer stabilizes after certain time of annealing. A multiplying factor termed as Diffusion Depth Factor (F) has been established and can be used to estimate the thickness of stabilized diffused layer formed during annealing by simply multiplying it with initial plating thickness.
\end{abstract}

Keywords: Homogenization annealing, Electroplating, Diffused layer, Brass wire

\section{INTRODUCTION:}

Electroplating of zinc on brass wire is an essential process to develop high end electrode wire for use in electric discharge machining (EDM). High zinc concentration at the surface of wire enhances the performance of the wire during sparking [1,2]. It is well known that electroplating gives rise to a mechanical bonding of $\mathrm{Zn}$ with brass wire and does not adhere with base wire rigidly. This is one of the major reasons that warrant homogenization annealing after electroplating in order to form a metallurgical bond. Homogenization annealing process at an elevated temperature is carried out in a controlled manner in order to achieve the enhancement of performance of the wire [3,4]. The process makes the coating layer stable and the wire becomes suitable for use as EDM wire.

Homogenization annealing activates solid state diffusion in between electroplated $\mathrm{Zn}$ and brass wire and forms diffused Zn enriched layer. Several investigations [5 - 7] 
have been carried out to understand and provide a better insight of diffusion process and associated movement of interface or boundary in diffusion couples with semiinfinite slab. It is known that diffusion characteristics of semi-infinite slab are not readily applicable to homogenization treatment when plating of a few microns is built up. The solute content in plated region has limited mass and its influence on diffusion process is not well documented. In the homogenization treatment of solids, the progress of two phase interface depends on solution of diffusion equations for both sides of the interface. In the present study, diffusion of solute does not obey solution of diffusion field equations of semi-infinite slabs as thickness of one phase is in few microns. In this paper, detailed study on diffusion of $\mathrm{Cu}$ and $\mathrm{Zn}$ atoms across the electrolytic interface in between brass and electroplated zinc has been carried out. The movements or growths of $\mathrm{Zn}$ rich diffused layer are observed in particular relevance to the development superior multilayer EDM wire.

\section{EXPERIMENTAL:}

The $\mathrm{Cu}-37 \mathrm{wt} \% \mathrm{Zn}$ alloy wire was prepared from $\mathrm{Cu}$ and $\mathrm{Zn}$ metal ingots (purity of $99.9 \%$ ) and drawn into round wire form of $0.618 \mathrm{~mm}$ diameter. Slices of $50 \mathrm{~mm}$ lengths were cut from the wire and electroplated with $\mathrm{Zn}$ from zinc sulphate electrolytic solution. The metallic zinc content of the solution is maintained in between 130 and $160 \mathrm{~g} / 1$. The current density is kept in range of 90 to $100 \mathrm{~mA} / \mathrm{cm}^{2}$ in order to get consistent coating of $\mathrm{Zn}$. The time of plating is varied in such a way to achieve 4,8 and $12 \mu \mathrm{m}$ coating thickness with $+/-0.25 \mu \mathrm{m}$. Several specimens were made under the same condition in order to ensure repeatability of results. The $\mathrm{Zn}$ plating thicknesses were measured by optical microscopy of cross-section of plated wire specimens.

The $\mathrm{Zn}$ plated specimens with three different plating thicknesses were subjected to diffusion annealing at $120^{\circ} \mathrm{C}, 160^{\circ} \mathrm{C}, 240^{\circ} \mathrm{C}, 240^{\circ} \mathrm{C}$ and $280^{\circ} \mathrm{C}$ for 2 to 8 hours in a closed oven. The specimens were kept in small closed vessels submerged in refined mineral oil in order to prevent oxidation and evaporation of $\mathrm{Zn}$ from the plated layer. The cross-sections of the diffused wire specimens were polished for the purpose of microstructure analysis and measurement of diffused coating thickness in scanning electron microscope (ZEISS).

\section{RESULTS \& DISCUSSIONS:}

Homogenization annealing of $\mathrm{Zn}$ plated wire at an elevated temperature induces zinc atoms of plating region to migrate across electroplating barrier and diffuse into base alloy due to composition gradient. Figure 1 indicates that $\mathrm{Zn}$ of electroplated layer forms $\mathrm{Zn}$ enriched diffused layer which increases with time. Due to this phenomenon, electroplating interface breaks down and becomes an interface in between zinc rich coating layer and alpha brass of base wire. The zinc rich diffused layer continues to increase in thickness with time and temperature. It is evident from figure $1 \mathrm{~b}$ and $1 \mathrm{c}$ that the depth of diffused layer increases with the increase of diffusion time. The 
initial plating thickness of $8 \mu \mathrm{m}$ becomes 12 to $13 \mu \mathrm{m}$ thick diffused layer after annealing of 2 hour at $200^{\circ} \mathrm{C}$, whereas, it is 15 to $16 \mu \mathrm{m}$ thick diffused layer after annealing of 6 hours at same temperature.
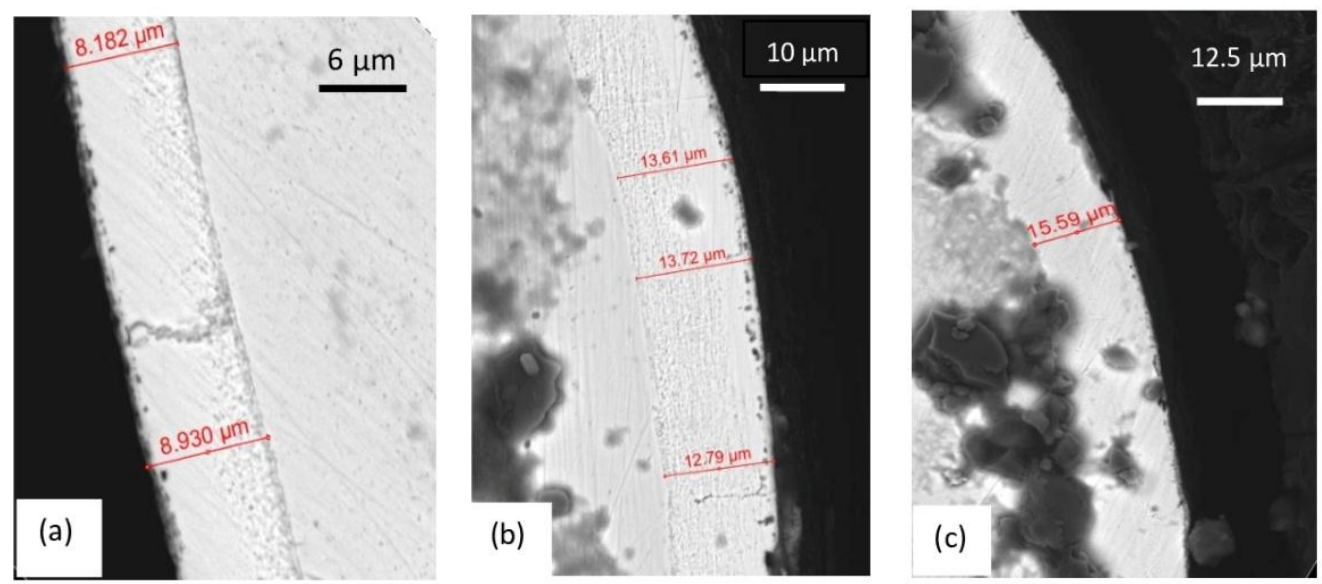

Figure 1: SEM images of $\mathrm{Zn}$ rich diffused layer after homogenization annealing (a) 4 hours at $200^{\circ} \mathrm{C}$ with initial plating of $4 \mu \mathrm{m}$ (b) 2 hours at $200^{\circ} \mathrm{C}$ with initial plating of 8 $\mu \mathrm{m}$ (c) 6 hours at $200^{\circ} \mathrm{C}$ with initial plating of $8 \mu \mathrm{m}$.
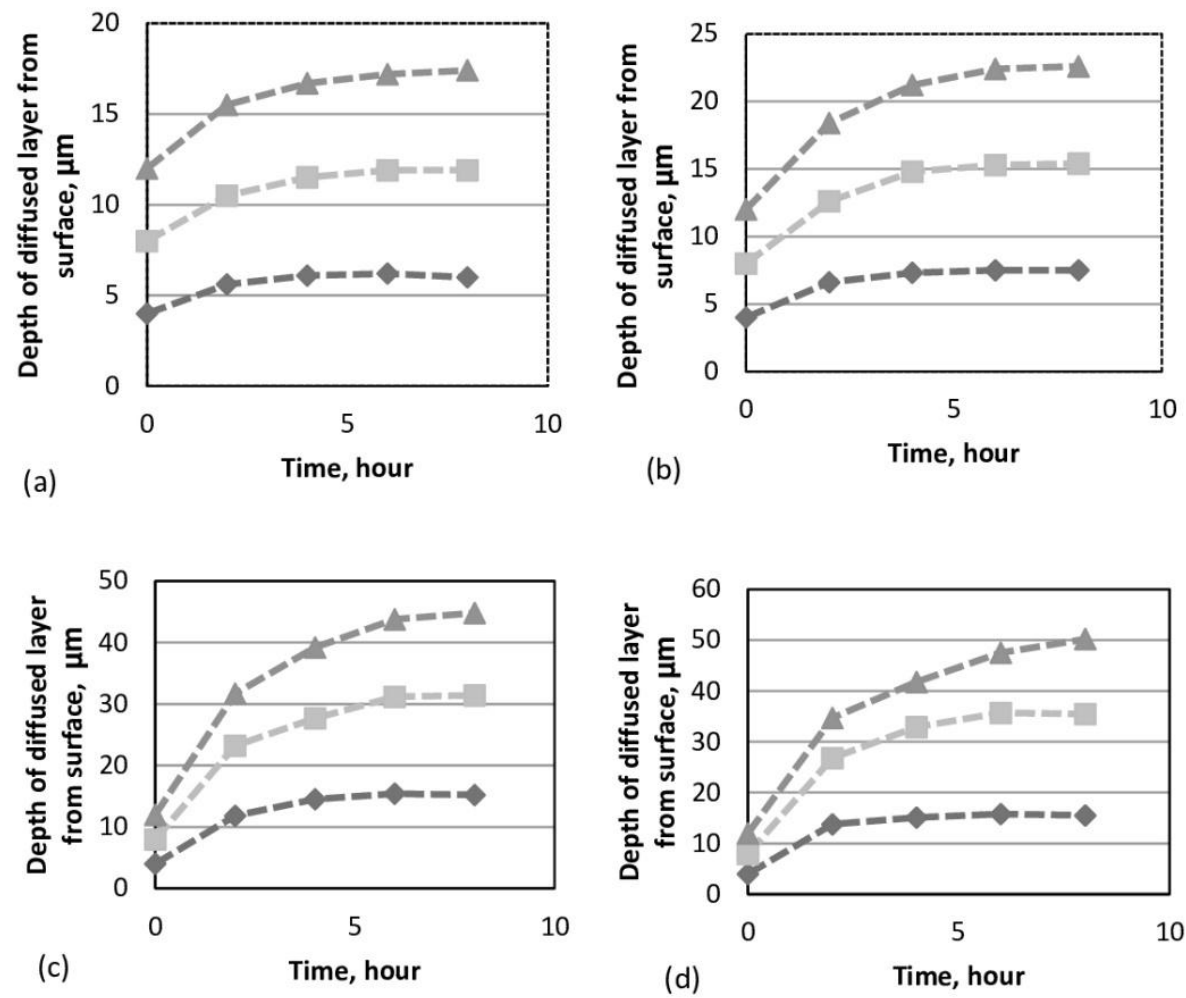

-44 micron plating $-\square-8$ micron plating $\quad-$ 늘 -12 micron plating

Figure 2: Variation of $\mathrm{Zn}$ rich diffused layer depth with time for different initial plating thickness annealed at (a) $160^{\circ} \mathrm{C}$ (b) $200^{\circ} \mathrm{C}$ (c) $240^{\circ} \mathrm{C}$ and (d) $280^{\circ} \mathrm{C}$. 
Figure 2 illustrates the growth of $\mathrm{Zn}$ rich diffused layer at different annealing temperature and time. It is observed that the depth of diffusion layer initially increases sharply with time however, it stabilizes after certain time. This suggests that the diffusion phenomenon is rapid at the beginning of annealing and stabilizes after certain time which may be attributed to thin layer of coating. The mass of zinc in electroplated layer is insufficient to penetrate further into base wire and therefore thickness of zinc rich diffused layer stabilizes.

Energy Dispersive X-ray Spectroscopy (EDS) analysis of the surface of diffused wires after annealing time of 6 hours is displayed in figure 3. It is observed in figure 3 that the composition of $\mathrm{Zn}$ in the diffused layer decreases with temperature. For annealing temperature above $240^{\circ} \mathrm{C}, \mathrm{Zn}$ composition attains $42 \mathrm{wt} \%$ to $46 \mathrm{wt} \%$ and the thickness of $\mathrm{Zn}$ enriched layer almost ceases to increase with time (cf. figure 2). It may be pointed out that the concentration gradient decays with time as more and more atoms cross the electrolytic interface at elevated temperature. This leads to increasingly sluggish diffusion process after 6 hours. This is particularly prevalent when the concentration difference in between the two sides of the interface becomes nominal [8] and inter-metallic compounds form. This phenomenon increases binding force locally and lowers mobility as well as driving force of solute atoms to such a level that the atoms do not posses sufficient energy to cross the interface $[4,7,8]$.

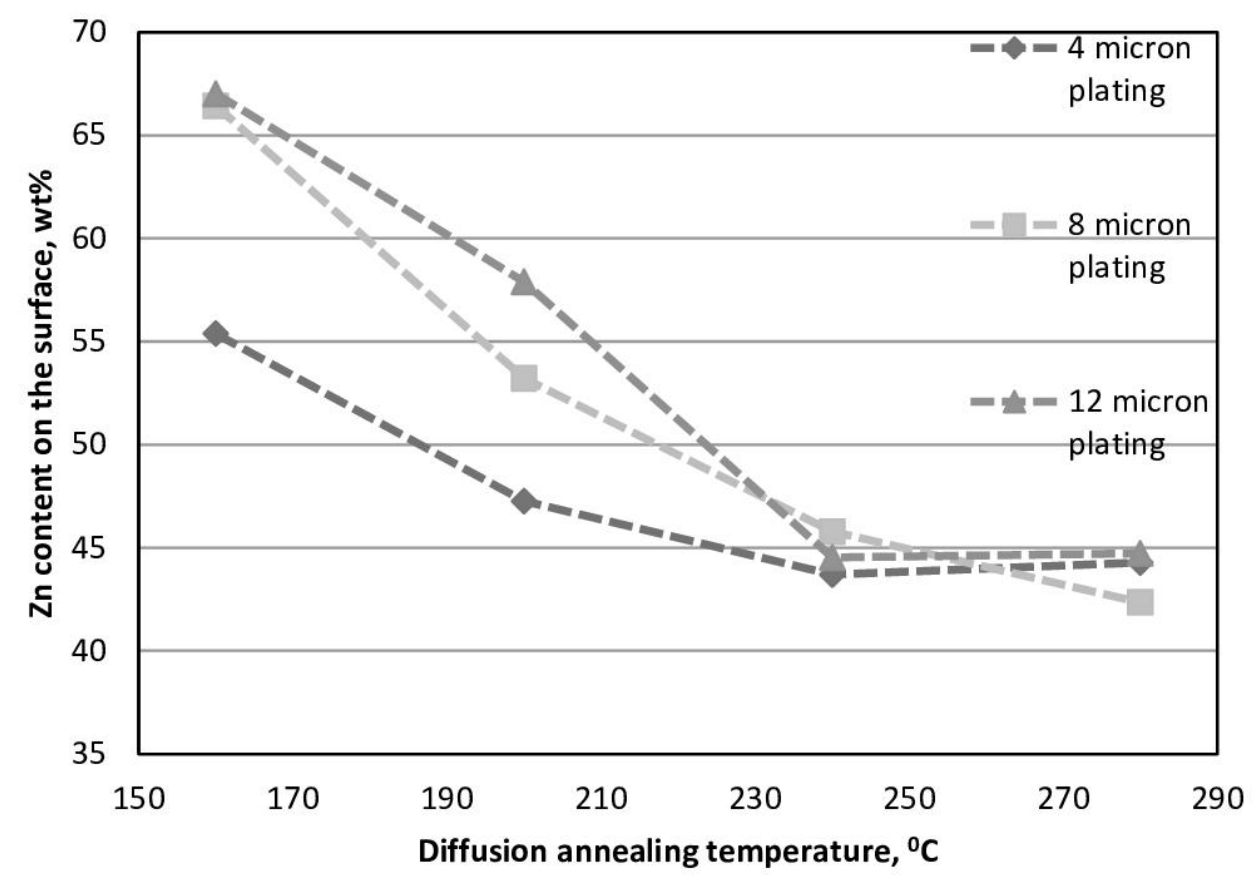

Figure 3: Plot of $\mathrm{Zn}$ content on wire surface Vs annealing temperature after 6 hours. 
It is evident that the thickness of diffused layer almost stabilizes after 6 hours of diffusion process for all initial plating thicknesses (cf. Figure 2). It is observed that for all initial plating thicknesses, depth of diffused layer grows by penetration into base wire by approximately 3.9 times and 4.6 times of thickness of initial plating at $240^{\circ} \mathrm{C}$ and $280^{\circ} \mathrm{C}$ respectively. Therefore, there appears to be a multiplying factor of diffusion depth and has been termed as Diffusion Depth Factor (F). This means that it is possible to estimate maximum or stabilized diffused thickness at a particular temperature by multiplying $\mathrm{F}$ with initial plating thickness. This suggests that $\mathrm{F}$ can be considered as an important basic property of a particular diffusion couple and is dependent on temperature of diffusion annealing. It can be used to estimate required depth of stabilized $\mathrm{Zn}$ rich diffused layer at particular temperature. Similar experiments have been carried out to corroborate $\mathrm{F}$ at other temperatures and results are shown in figure 4.

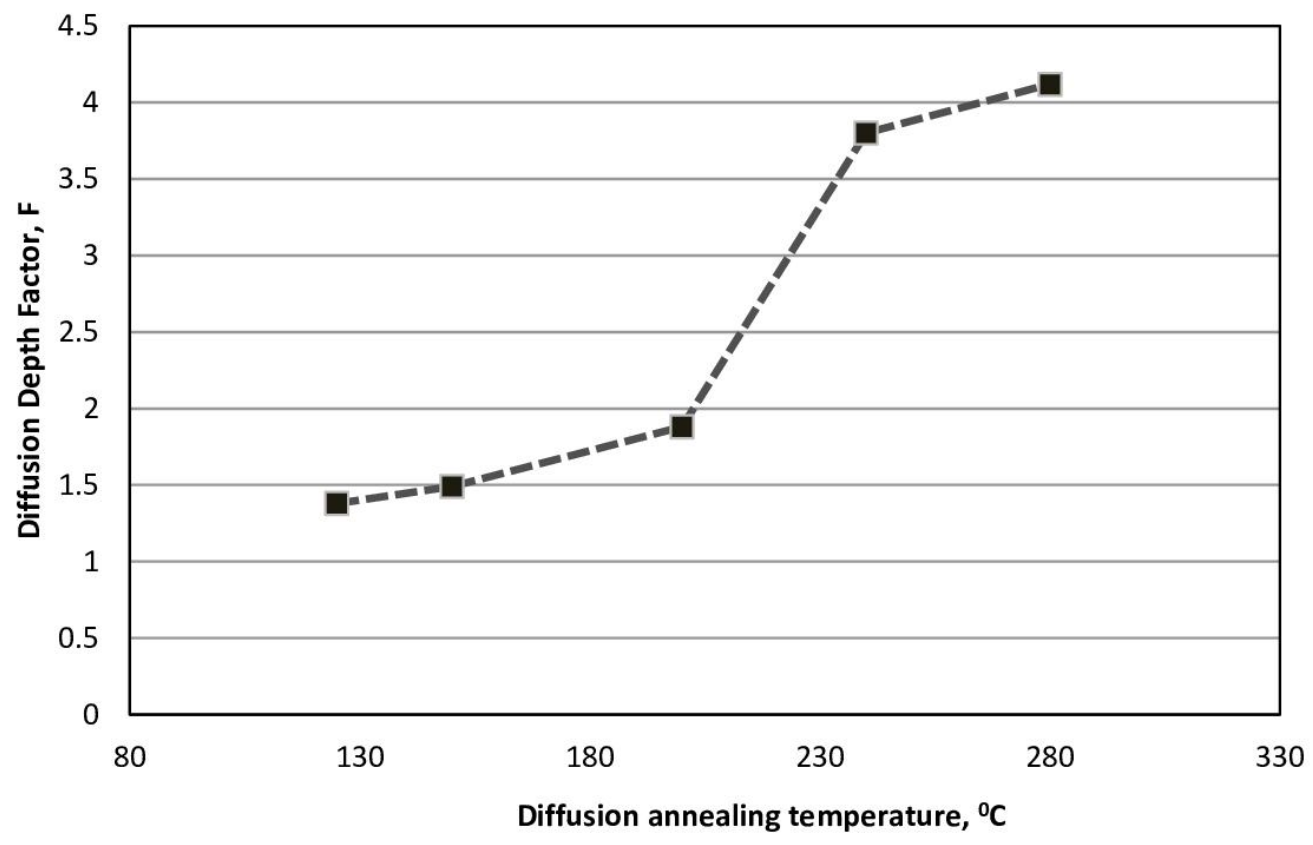

Figure 4: Variation of $\mathrm{F}$ with diffusion annealing temperature.

It is observed in figure 4 that Diffusion Depth Factor $(\mathrm{F})$ increases very sharply with increase of temperature above $200^{\circ} \mathrm{C}$. This suggests that above annealing temperature of $200^{\circ} \mathrm{C}$, threshold energy for the onset of significant migration of $\mathrm{Cu}$ and $\mathrm{Zn}$ atoms is attained in solid state structure of brass.

\section{CONCLUSIONS:}

1. Extensive experiments have been carried out to understand the growth of $\mathrm{Zn}$ rich diffused layer during homogenization annealing treatment of $\mathrm{Zn}$ plated brass wire. It is observed that depth of zinc rich diffused layer initially increases with time 
and then stabilizes after particular time of diffusion annealing depending upon temperature of diffusion. The zinc concentration on surface of diffused wire steadily decreases with increase of temperature. For annealing temperature above $240^{\circ} \mathrm{C}, \mathrm{Zn}$ content of stabilized diffused layer attains $42 \mathrm{wt} \%$ to $46 \mathrm{wt} \%$ on the surface of the wire.

2. Diffusion Depth Factor (F) is the ratio of depth of stabilized diffused layer and initial zinc plating thickness. Experiments have shown that $\mathrm{F}$ is dependent on temperature of diffusion and increases sharply with enhancement of temperature of diffusion annealing above $200^{\circ} \mathrm{C}$.

\section{ACKNOWLEDGEMENT}

The author would like to thank Prof. J.D. Majumder, Dept. of Metallurgical and Materials Engineering, Indian Institute of Technology, Kharagpur, India for the use of SEM facility.

\section{REFERENCES:}

[1] P. C. Pandey. and H. S. Shan, Modern machining processes, Tata - McGrew Hill Publishing Co. NY, (1980), $79-81$.

[2] J. Kapoor, S. Singh and J. S. Khamba, Recent developments in wire electrodes for high performance WEDM, Proc. Of the World Congress on Engg. Vol II (2010), 1065-68.

[3] D. S. Tomalin, US Patent no US5945010 (1999).

[4] D. S. Tomalin, US Patent no US8067689 B2 (2011).

[5] A. D. Smigelskas and E. O. Kirkendall, Zinc diffusion in alpha brass. Trans. AIME 171 (1947), 130 - 142.

[6] R. Nakamura, K Fujita, Y. Liji, M. Okada, Diffusion mechanism in B2 NiAl phase studied by experiments on Kirkendall effect and interdiffusion under high pressure. Acta Materialia 51 (2003), 3861 -70.

[7] H. Mehrer, Diffusions In Solids (Fundamentals, Methods, Materials Diffusion Controlled Processes), Springer - Verlag Berlin, Heidelburg (2007).

[8] D. Gaertner et.al, Concentration - dependent atomic mobility in FCC CoCrFeMnNi high enthalpy alloys, Acta Materialia, 166 (2019), 357-70. 